\title{
I. SELECTION INTENSITY, GENERATION INTERVAL AND INDEXES IN RETROSPECT
}

\author{
L.N. NWAKALOR ${ }^{1}$, J.S. BRINKS ${ }^{2}$ and G.V. RICHARDSON ${ }^{3}$ \\ Colorado State University, Fort Collins U.S.A.
}

\section{SUMMARY}

Selection intensity and generation interval were evaluated in a Hereford cattle herd of 14 inbred lines and 14 linecross groups corresponding to the lines of inbred sire at the San Juan Basin Research Centre, Hesperus, Colorado. Selection indexes practised were calculated in retrospect. The records analysed were weaning weight and postweaning traits in males and females collected from 1946 through 1973. Analyses were performed by line for the inbreds and pooled analyses for the inbred and linecrosts populations.

From records of 1,239 calves weaned, age of sire averaged 3.75 years compared with 4.52 years for age of dam, showing faster generation turnover for sires thon for dams. Generation interval determined as actual age of midparent was $\mathbf{4 . 1 3}$ years.

Selection applied, evaluated as annusl selection differentials within inbred lines and then pooled over all lines, averaged $\mathbf{. 5 5}$ standard deviations per generation for sires for weaning weight. Selection of females was much less. Midparent selection differential amounted to .33 standard deviations per generaton.

Pooled standardized selection differentials per generntion over all lines for sires were $.49, .46, .40$, $-.20,-.10$, and .69 , respectively, for initiol weight, finial weight, feed consumption, unadjusted feed efflelency, adfasted feed efficiency, and average daily gin. Selection of females for postweaning traits was not intense.

Selection indexes actually practiced in retrospect were: for sires, $I_{S}=.4661(W W)-.0992(F E)+$ .6126(ADG); for inbred dams, $I_{\mathrm{p}}=.1824(\mathrm{WW})$ $-.0284(12 W)+.0736(18 W)-.1697$ (SPW) -.1097 (FAW); for linecross dams, $I_{D}=.2693$ (WW) $-.2960(12 W)+.0147(18 W)+.1185(S P W)-.0354$ (FAW). The corresponding index selection differentials were $.818, .203$, and .209 . Sire index selection differntials represent about 79 percent of the total selection differentials.

Present address: Department of Animal Science, University of Nigeria, Nsukka, Nigeria.

2 Professor, Department of Animal Sciences, Colorado State University, Fort Collins, CO 80521, U.S.A.

${ }^{3}$ Biometrician, SEA, USDA, Fort Collins, CO 80521 , U.S.A.

\section{INTRODUCTION}

Genetic response to selection depends on the extent parents deviate from average, the average genetic variation and covariation of all traits directly or indirectly related to traits under selection, and the interval between selected generations. Selection for manifold objectives may be aided by calculating the phenotypic selection differential for each component character for comparison with the actual response obtained: In any population the smaller the proportion of antmals selected as parents, the greater will be the selection differential provided that those selected come from the upper segment of the merit scale for the trait involved.

Generation interval is usually calculated as the average age of parents when their offsprings are born. Longevity in parental stock will increase the generation interval but will make more data available on the parents and thus lead to greater accuracy of selection and increased selection differential. Usually a balance must be struck between the generation interval and maximum data which increase progress per generation (Preston and Willis, 1974; James, 1972).

This study attempts to evaluate the intensity of selection practised for weaning weight and postweaning traits and the generation interval in males and females at San Juan Basin Research Centre Hereford herd. Selection indexes are also calculated in retrospect. The results as well as their applicability to beef cattle breeding in. Nigeria are discussed.

Nigerian Journal of Animal Production 8(2) 1981. 


\section{MATERLAXS AND METHODS}

Location of study. This study was carried out with a Hereford cattle herd at the San Juan Basin Research Centre, Hesperus, Colorado, U.S.A. The station is situated at an elevation of 2316 meters above sea level and has a grazing area comprising 2340 ha of native oakbrush rangeland, 150 ha of irrigated farmland and 19 ha of dry seeded pasture. The climate is temperate, with an average annual precipitation of $46.7 \mathrm{~cm}$, most of which falls as snow in the winter months (December - February), and average annual temperature ranging from a maximum of $37.2^{\circ} \mathrm{C}$ in summer (June -August) to a minimum of $-36.0^{\circ} \mathrm{C}$ in winter. Average relative humidity varies from $52.5 \%$ in January to $42 \%$ in July.

Breeding system. The breeding project was started in 1946 with the primary purpose to study the prospects for the utilization of heterosis in commercial beef production. Over the years 14 established inbred lines of Hereford cattle were used in reciprocal crossing to produce 14 linecross groups corresponding to the lines of inbred sire. Linecross cows were mated to performance tested inbred bulls to produce linecross progeny. By 1973 the average inbreeding levels in the herd were 25.5 and 36.3 percent for dam and calf. Whereas the foundation cows and sires for lines $4,6,7,8,10,11$ and 12 were of Fort Lewis (line 6) breeding, those used in lines $1,2,3,5,9$ and 14 were purchased from private breeders. 'Line 15 foundation animals were of Colorado State College breeding. The mating scheme used to initiate most of the lines was sire $\mathrm{x}$ daughter mating.

Selection of Replacements. Until 1967 the breeding season extended 90 days from early June to early September. From 1968 the season was shortened to 60 days from mid-May - mid-July. Weaning of calves was done in late October or early November at about $\mathbf{2 0 0}$ days of age. After weaning about one-third of heifers were retained for breeding. Factors considered in selecting replacements were age, weight and the replacement need within particular line or linecross group.

Selection of herd sires was done within lines. Select criteria have been outlined by Nwakalor et al (1976).

Performance Traits. Weaning weight was adjusted for sex, age and age of dam in one case, and for these factors in addition to inbreeding of calf and dam in another case. Adjustment factors used were those derived for the herd by Harwin (1963). Postweaning traits of males include initial test weight, final weight, feed consumption, feed efficiency for 140-day test (adjusted and unadjusted to midweight on test) and average daily gain over the test period. Postweaning traits of females comprise gain from weaning to 12 months, 12-month weight (adjusted to 365 days), gain from 12 to 18 months, 18-month weight (adjusted to 550 days), and mature weights in spring, summer and fall. Mature cow weight data were analyzed by least squares procedures for the effects of year of record, age of cow when weight was taken and lactation status. Age classes ranged from 1 to $10+$ and lactation status from 1 to 4 .

From preliminary analyses the weightby-age class constants for all three mature weights showed that cows continue to gain weight until 8 years of age, and then decline slightly thereafter, as shown by the Miles City study of Brinks et al. (1962). All three effects were highly significant $(P<.01)$ thus the individual female weights from ages of 2 through $10+$ were adjusted for these effects using the derived least squares constants. Adjustment for age of cow was made to 8 year-old equivalent while lactation status was adjusted to a wet-wet (in consecutive years) basis. Average mature weights were obtained for individual cows as the average of weights taken from 2 to $10+$ years of 
age, after adjustments.

Evaluation of Selection Applied. Selection applied was measured as the average annual selection differential of parents ( $\Delta P$ ), which is the different ir $\rightarrow$ ean performance of selected parents compared with the average of the unselected group from which they came, divided by the average age of parents (A) when off-spring were born. Annual selection differentials were computed within lines separately for sires ( $\Delta S$ ) and dams ( $\Delta D$ ), and because each se of parent contributes equally to the genetic composition of the progeny in the next generation, the net selection differential was the unweighted average of sire and dam.

Formulas used for calculating annual selection differentials were those presented by Dickerson and Hazel (1944), Dickerson et al. (1954), Rendel and Robertson (1950) and Brink et al (1965). The formulae which account for sequential culling over years of animals from the herd are:

$$
\begin{aligned}
\Delta S & =\frac{\sum n_{i} s_{i}}{N A} \\
\Delta D & =\frac{n_{j} d_{j}}{N A} \\
\Delta P & =\quad \frac{\Delta S+\Delta D}{2} \\
\text { and } \bar{A} & =\frac{\sum n_{i} A_{i}+\sum n_{j} A_{j}}{2 N}
\end{aligned}
$$

or the average age of parents when offspring are born:

where $\mathbf{n}_{\mathbf{i}}$ and $\mathbf{n}_{\mathbf{j}}$ are the number of progeny by a particular sire and dam, respectively, in a given year; $s_{i}$ and $d_{j}$ are the superiority or inferiority of a particular sire and dam measured as the deviation from the mean of the unselected group in which they were born; and $N$ is the number of progeny in a given year.

Only those animáls whose sires and dams were born within the respective lines (apart from foundation parents) were used in calculating selection differentials. Foundation animals were assigned a selection differential of zero and an age at the time offspring were born equal to the number of years after the line was started, for calculating their contribution to annual selection differentials. Parents born at the time the line was started or later were assigned their actual ages.

Annual selection differentials were computed separately for inbred sires, inbred females and linecross females. Values for respective lines, weighted by the number of offsprings contributed by each line, were pooled to obtain the overall annual selection differentials for the herd. Mean annual selection differential was taken as unweighted average over all years. Selection differentials were not calculated for the early years of each line when all of either male or female parents were foundation animals and performance records were not available on them.

Selection Indexes in Retrospect. The correlation matrix multiplication procedure of Harvey and Bearden (1962) was used to compute the selection indexes actually employed in retrospect. The phenotypic correlation matrix (as the independent variables) was equated to the selection differential in standard units matrix (as the dependent variable). Solution of the equations yielded $a_{i}$ (the relative weight expressed as standard partial regression coefficients). Indexes so,

obtained give each characteristic the average emphasis it actually had during selection. Selection differential in standard measure for the index actually practiced was calculated from the formula.

$$
\begin{aligned}
& I=\left(a_{1} s_{1}+a_{2} s_{2}+\ldots+a_{n} s_{n}\right)^{1 / 2} \\
& \text { (Harvey and Bearden, 1962). } \\
& \text { The phonetypic correlations used in this } \\
& \text { study were obtained from the studies of } \\
& \text { Petty and Cartwright (1966), Armstrong }
\end{aligned}
$$


SELECTION INTENSITY AND GEN

(1964), Brinks et al. (1964), and Preston and Willis (1974).

\section{RESULTS AND DISCUSSION}

\section{Analysis by Line}

Age of Parents. Average ages of parents are given by line in Table 1. Weaning weight records show that in 8 of the 12 lines used average age of dams was greater than that of sires, indicating faster replacement rates for sires. Ages of sires and dams in lines $2,6,7$ and 14 suggest slightly more rapid replacement rates of dams than of sires, resulting from the use of older sires than dams. Generation interval ranged from 2.00 years in line 7 to 5.83 years in line 15 , results which show substantial differences in parent age between lines for weaning weight.

Average parent ages calculated from postweaning records of males and females
INTERVAL IN HEREFORD CATTLE.

were similar to those for weaning weight. In general, generation turnover was faster for sires than for dams.

Selection Differentials. Mean selection differentials in standard units per generation for weaning weight (table 2) ranged from -1.70 in line 6 to 1.85 in line 2 for males when the data was unadjusted for inbreeding effects. Lesser pressure was applied in female selection, although selection differentials were positive for all lines. Mid-parent selection differentials were all positive except for line 6 , and represent a range of saving from the lower 54 percent to the upper 36 percent under truncation selection. Selection pressure patterns for weaning weight adjusted for inbreeding were similar to those for data unadjusted for inbreeding and serve as evidence that no direct attention was given to the level of inbreeding in selecting individual replacements.

TABLE 1.

Average Age of Parents (yrs.) of inbred Progeny used to calculate annual Selection defferentinls for Weaning Wejgbt and Postweaning Traits by Line

\begin{tabular}{|c|c|c|c|c|c|c|c|c|c|c|c|c|c|c|}
\hline \multirow{3}{*}{\multicolumn{2}{|c|}{ Line }} & \multirow{3}{*}{$\begin{array}{l}\text { No. of } \\
\text { Progeny }\end{array}$} & \multicolumn{4}{|c|}{ Weaning Weight } & \multicolumn{3}{|c|}{$\begin{array}{c}\text { Postweaning Traits } \\
\text { of Moles" }\end{array}$} & \multicolumn{5}{|c|}{$\begin{array}{c}\text { Postweaning Traits } \\
\text { of Females }{ }^{b}\end{array}$} \\
\hline & & & & \multirow{3}{*}{ Sire } & \multicolumn{2}{|c|}{ Age } & \multirow{2}{*}{$\begin{array}{l}\text { No. of } \\
\text { Progeny }\end{array}$} & \multicolumn{2}{|c|}{ Age } & \multicolumn{2}{|r|}{ No. of } & \multicolumn{2}{|r|}{ Age } & \multirow[b]{2}{*}{$\bar{A}$} \\
\hline & & & & & Dam & $\overline{\mathbf{A}}$ & & Sire & Danı & $\overline{\mathbf{A}}$ & Progeny & Sire & Dam & \\
\hline 1 & Anim & - & & & - & - & - & - & - & - & - & - & - & - \\
\hline 2 & Bon & 33 & & 3.00 & 2.99 & 3.00 & 10 & 3.33 & 3.78 & 3.56 & 5 & 3.50 & 3.00 & 3.25 \\
\hline 3 & BA & 202 & & 3.76 & 4.65 & 4.20 & 58 & 4.19 & 5.02 & 4.61 & 56 & 3.56 & 5.48 & 4.52 \\
\hline 4 & Colo & 80 & & 3.59 & 5.01 & 4.30 & 31 & 3.47 & 5.84 & 4.65 & 25 & 3.64 & 4.67 & 4.16 \\
\hline$\varsigma$ & Don & 117 & & 3.95 & 5.02 & 4.48 & 34 & 4.03 & 4.43 & 4.23 & 32 & 4. 18 & 5.41 & 4.79 \\
\hline 6 & Ft Leu & 61 & & 3.03 & 2.07 & 2.55 & - & - & - & - & 17 & 3.33 & 1.78 & 2.56 \\
\hline 7 & La PI & 37 & & 2.00 & 1.99 & 2.00 & 10 & 2.00 & 2.25 & 2.13 & 10 & 2.00 & 1.85 & 1.93 \\
\hline 8 & Mesa & - & & - & - & - & - & - & - & - & - & - & - & 一 \\
\hline 9 & Mon & 141 & & 3.72 & 5.57 & 4.64 & 44 & 3.72 & 5.33 & 4.53 & 25 & 3.75 & 6.17 & 4.96 \\
\hline 10 & Pros & 126 & . & 4.14 & 5.41 & 4.77 & 47 & 4.76 & s.as & 4.90 & 34 & 3.58 & 5.47 & 4.52 \\
\hline 11 & Roy & 138 & & 4.48 & 4.68 & 4.58 & 46 & 5.17 & 5.32 & 5.25 & 34 & 5.13 & 4.73 & 4.93 \\
\hline 12 & $\mathrm{~S} J$ & 166 & & 3.91 & 4.95 & 4.43 & 54 & 3.76 & 5.03 & 4.40 & 44 & 4.13 & 6.12 & 5.13 \\
\hline 14 & Tarr & 105 & & 4.05 & 3.79 & 3.92 & 46 & 3.99 & 4.52 & 4.26 & 29 & 3.72 & 4.13 & 3.92 \\
\hline is & $R P$ & 31 & & 4.82 & 6.84 & 5.83 & 10 & 5.00 & 2.97 & 3.98 & 15 & 4.67 & 6.58 & 5.63 \\
\hline
\end{tabular}

${ }^{3}$ Based on Initial Weight records.

bBased on Mature Summer Weight records. 
NWAKALOR ETAL

TABLE 2.

Selection Defferential in standard Units per Generation of inbred Males and Females for adjusted Weaning Weight by Line

\begin{tabular}{|c|c|c|c|c|c|c|c|c|}
\hline \multirow[b]{2}{*}{ Line } & & \multicolumn{3}{|c|}{ Unadj. for Inbreeding } & \multicolumn{3}{|c|}{ Adjusted for Inbreeding } & \\
\hline & & $\Delta I S$ & $\triangle \mathbf{D}$ & $\Delta P$ & $\Delta s$ & 180 & $\Delta P$ & \\
\hline 1 & Anim & & & & - & - & - & \\
\hline 2 & Bon & 1.85 & .23 & 1.04 & 1.84 & .24 & 1.04 & \\
\hline 3 & $\mathbf{B A}$ & .76 & .06 & .41 & .81 & .00 & .41 & \\
\hline 4 & Colo & .88 & .00 & .44 & .96 & -.05 & .46 & \\
\hline 5 & Don & .55 & .10 & .32 & .54 & .05 & .29 & \\
\hline 6 & Ft Lew & -1.70 & .22 & .74 & -1.48 & .21 & .63 & \\
\hline 7 & La PI & -.11 & .13 & .02 & -.13 & .13 & .00 & \\
\hline 8 & Mesa & - & - & - & - & - & - & \\
\hline 9 & Mon & $1.06^{\circ}$ & .38 & $.7 z$ & 1.10 & .32 & .71 & \\
\hline 10 & Pros & 1.41 & .08 & .74 & 1.29 & .02 & .65 & \\
\hline 11. & Roy & .58 & .37 & .47 & .67 & .34 & .51 & \\
\hline 12 & SJ & .81 & .25 & .54 & .86 & .19 & .53 & \\
\hline 14 & Tatr & .89 & .09 & .49 & .91 & .03 & .47 & \\
\hline 15 & $\mathbf{R P}$ & .14 & .29 & .22 & 01 & .26 & 14 & \\
\hline
\end{tabular}

TABLE 3

Selection Differentials of inbred Males and Females (per Generation in Standard Units) for Postweaning Traits by Line

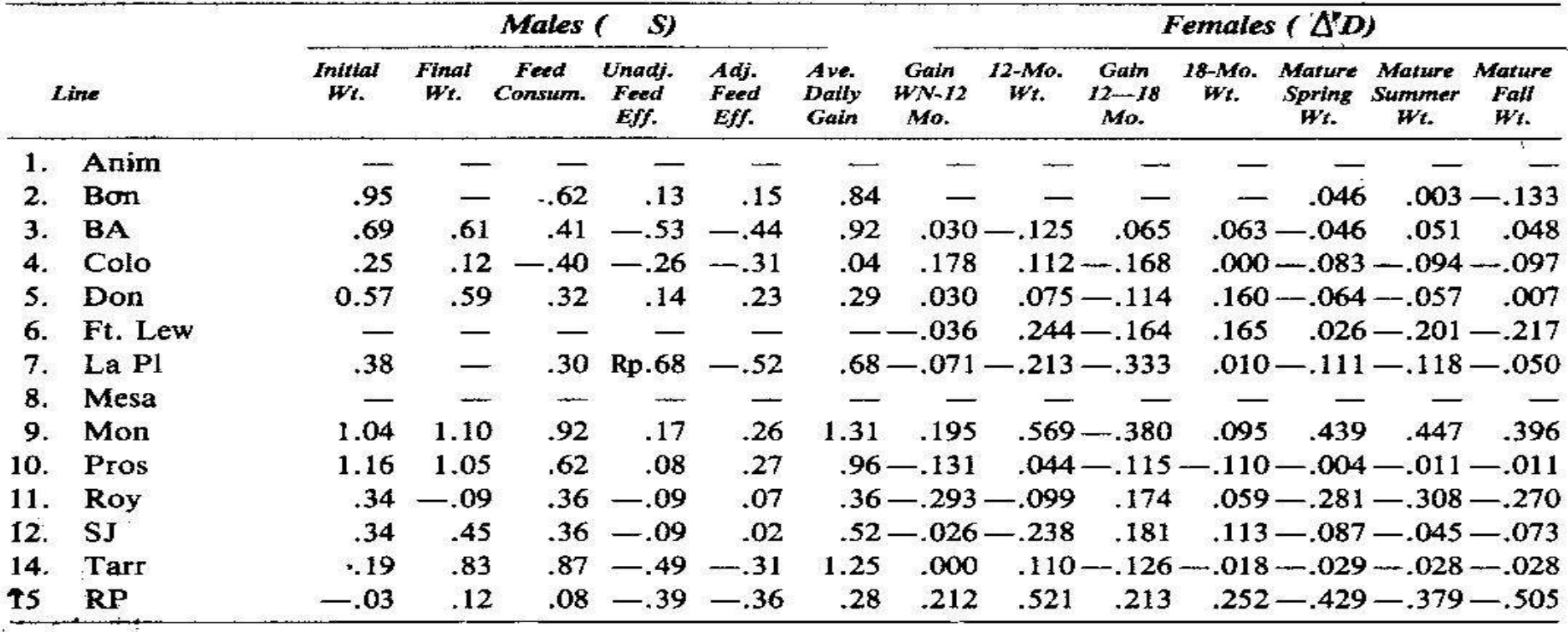

Selection differential of sires for postweaning traits of males (table 3) was positive for most lines for initial weight, final weight, feed sonsumption and average daily gain. Selection for feed efficiency was negative for several lines, with negative values representing positive selection differentials. Standardized selection differentials per generation for inbred females show little selection of females for postweaning traits. In fact, negative selection was practised for most lines, especially for mature weights, pointing that individuals selected to be parents were chosen from the bottom segment of the population.

\section{Overall Analysis.}

Weaning Weight. Average ages of parents based on weaning weight records are listed ip table 4. From a total of 1,239 records for the inbred males and females age of sire averaged 3.75 years compared with 4.52 years for age of dam. Genera- 
tion interval determined as actual age of midparent amounted to 4.13 years. As would be expected, replacement rates were faster for sires than for dams. Ages of parents of the linecross females were similar to those of inbred animals, being 3.57 years for sires and 4.85 years for tams with a value of 4.21 years for midparent. These values are within the ranges reported by Brinks, Clark and Kieffer (1965), Koch et al (1974), Armstrong (1964), and Flower et al. (1964). As in the present study they reported faster replacement rates for sires than for dams.

Annual selection differentials of sires and dams for weaning weight (unadjusted and adjusted for inbreeding) are shown in table 5 . The values for sires were similar in the two cases and averaged 3.4 and 3.7 $\mathrm{kg}$ per year or .50 and .55 standard deviations per generation, corresponding to selecting the upper 68 percent of the male population. Selection pressure for inbred females were 1.0 and $.8 \mathrm{~kg}$ per year or about three and one-half times and five times, respectively, smaller than for sires. These correspond to standardized selection differentials per generation of .15 and .11 , with those selected representing the top 92 percent of the inbred female population. Mid-parent annual selection differential amounted to $2.2 \mathrm{~kg}$ in each case and was equivalent to .33 standard deviations per generation and selection of the top 78 percent of the population. The

TABLE 4

Average Age of Parents (years) calculated from Weaning Weight Records

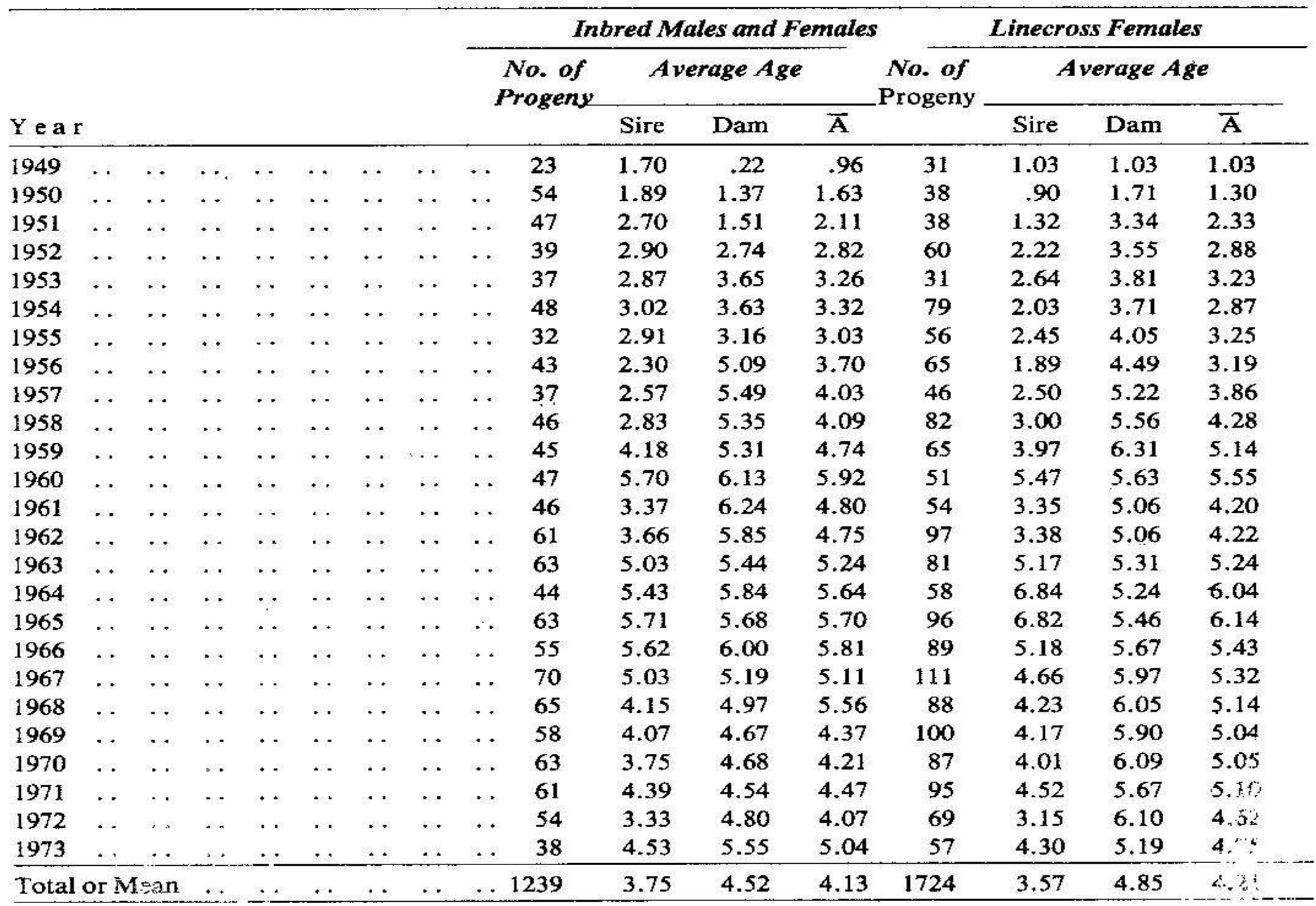


NWAKALOR $E T A L$

similar selection pressure patterns ror adjusted weaning weight in the two cases (unadjusted and adjusted for inbreeding) again is evidence that no direct attention was given to the level of inbreeding during selection.

\section{TABLE 5}

Pooled annual Selection Differentials ${ }^{-}(\mathrm{kg})$ for adjusted Weaning Weight ${ }^{\mathrm{a}}$

\begin{tabular}{|c|c|c|c|c|c|c|c|}
\hline \multirow[b]{3}{*}{ Year } & \multicolumn{6}{|c|}{ Inbred Males and Females } & \multirow{3}{*}{$\begin{array}{c}\text { Linecross } \\
\text { Females } \\
\Delta D\end{array}$} \\
\hline & \multicolumn{3}{|c|}{ Adj. WW(Unadj. for Fx) } & \multicolumn{3}{|c|}{ Adj. WW(Adj. for $F x)$} & \\
\hline & $\Delta \mathrm{s}$ & $\Delta_{\mathrm{D}}$ & $\Delta P$ & $\triangle S$ & D & $\Delta P$ & \\
\hline 1949 & -17.6 &. .1 & -8.8 & -15.2 & .1 & -7.6 & 1.2 \\
\hline 1950 & -2.5 & .5 & -1.0 & -1.9 & .3 & -.8 & 2.5 \\
\hline 1951 & -2.8 & 2.3 & -.2 & -2.2 & 2.3 & .0 & .8 \\
\hline 1952 & 1.4 & 1.6 & 1.5 & 2.0 & 1.4 & 1.7 & 1.1 \\
\hline 1953 & -.9 & 1.5 & .3 & -.4 & 1.3 & .5 & 1.3 \\
\hline 1954 & 4.5 & -.2 & 2.1 & 4.3 & -.3 & 2.0 & 1.1 \\
\hline 1955 & -1.6 & 1.1 & -.2 & -1.4 & .9 & -.3 & 1.5 \\
\hline 1956 & 4.4 & 1.2 & 2.8 & 4.5 & .9 & 2.7 & 1.0 \\
\hline 1957 & 8.9 & 1.5 & 5.2 & 8.8 & 1.2 & 5.0 & .8 \\
\hline 1958 & 9.6 & .4 & 5.0 & 9.8 & .0 & 4.9 & .7 \\
\hline 1959 & 6.6 & 1.0 & 3.8 & 6.6 & .7 & 3.6 & .0 \\
\hline 1960 & 5.7 & 1.0 & 3.4 & 5.6 & .9 & 3.2 & .5 \\
\hline 1961 & 5.8 & 1.2 & 3.5 & 5.6 & $1.0^{\circ}$ & 3.3 & .6 \\
\hline 1962 & 5.7 & .7 & 3.2 & 5.8 & .4 & 3.1 & -.1 \\
\hline 1963 & 4.2 & .7 & 2.5 & 4.4 & .5 & 2.5 & -.2 \\
\hline 1964 & 4.0 & .9 & 2.5 & 4.1 & .8 & 2.5 & .1 \\
\hline 1965 & 4.5 & .8 & 2.4 & 3.9 & .5 & 2.2 & .0 \\
\hline 1966 & 4.0 & -.1 & 2.0 & 3.8 & .4 & 1.7 & .0 \\
\hline 1967 & 4.5 & .5 & 2.5 & 4.6 & .1 & 2.4 & -.2 \\
\hline 1968 & 4.0 & .5 & 2.2 & 4.3 & .0 & 2.2 & -.2 \\
\hline 1969 & 5.6 & 1.2 & 3.5 & 6.3 & .8 & 3.5 & .1 \\
\hline 1970 & 6.6 & .9 & 3.8 & 6.8 & .4 & 3.6 & .5 \\
\hline 1971 & 6.5 & 2.1 & 4.3 & 6.7 & 1.6 & 4.2 & .3 \\
\hline 1972 & 8.1 & 3.2 & 5.6 & 8.3 & 2.5 & 5.4 & 1.0 \\
\hline 1973 & 6.1 & 1.5 & 3.8 & 6.4 & .9 & 3.6 & 1.4 \\
\hline Mean per $y r$. in actual units & 3.4 & 1.0 & 2.2 & 3.7 & .8 & 2.2 & .6 \\
\hline Mean per gen. in actual units & 14.1 & 4.3 & 9.2 & 15.2 & 3.2 & 9.2 & 2.7 \\
\hline Mean per gen. in std. units & .50 & .15 & .33 & .55 & .11 & .33 & .10 \\
\hline Truncated Value $\%$ & 69 & 92 & 78 & 67 & 93 & 78 & 95 \\
\hline Std. dev. & & & 27.9 & & & 27.8 & 26.2 \\
\hline
\end{tabular}

$a_{\text {No. of progeny by year is same as in Table } 4}$

Selection differentials of linecross females averaged $.6 \mathrm{~kg}$ per year. Standardized selection differentials per generation amounted to .10 with the truncated selection value representing the upper 95 percent of the linecross female population. This indicates slightly less selection for linecross than inbred females for weaning weight. 


\section{SELECTION INTENSITY AND GEN}

The greater consistency in selection differential trend after 1955 probably reflects and change of the selection index that took place after that year. Moreover, the culling of lines 6,7 and 8 from the herd in 1955 for lower than average pro-
INTERVAL IY HEREFORD CATTLE.

ductivity probably resulted in better stabilization of performance in the herd. The effect of both events was demonstrated in a previous study (Nwakalor et al 1976) where a strong upward genetic trend was reported for weaning weight.

TABLE 6

Pooled annual Selection Differentials over all Lines for Postweaning Traits of inbred Males

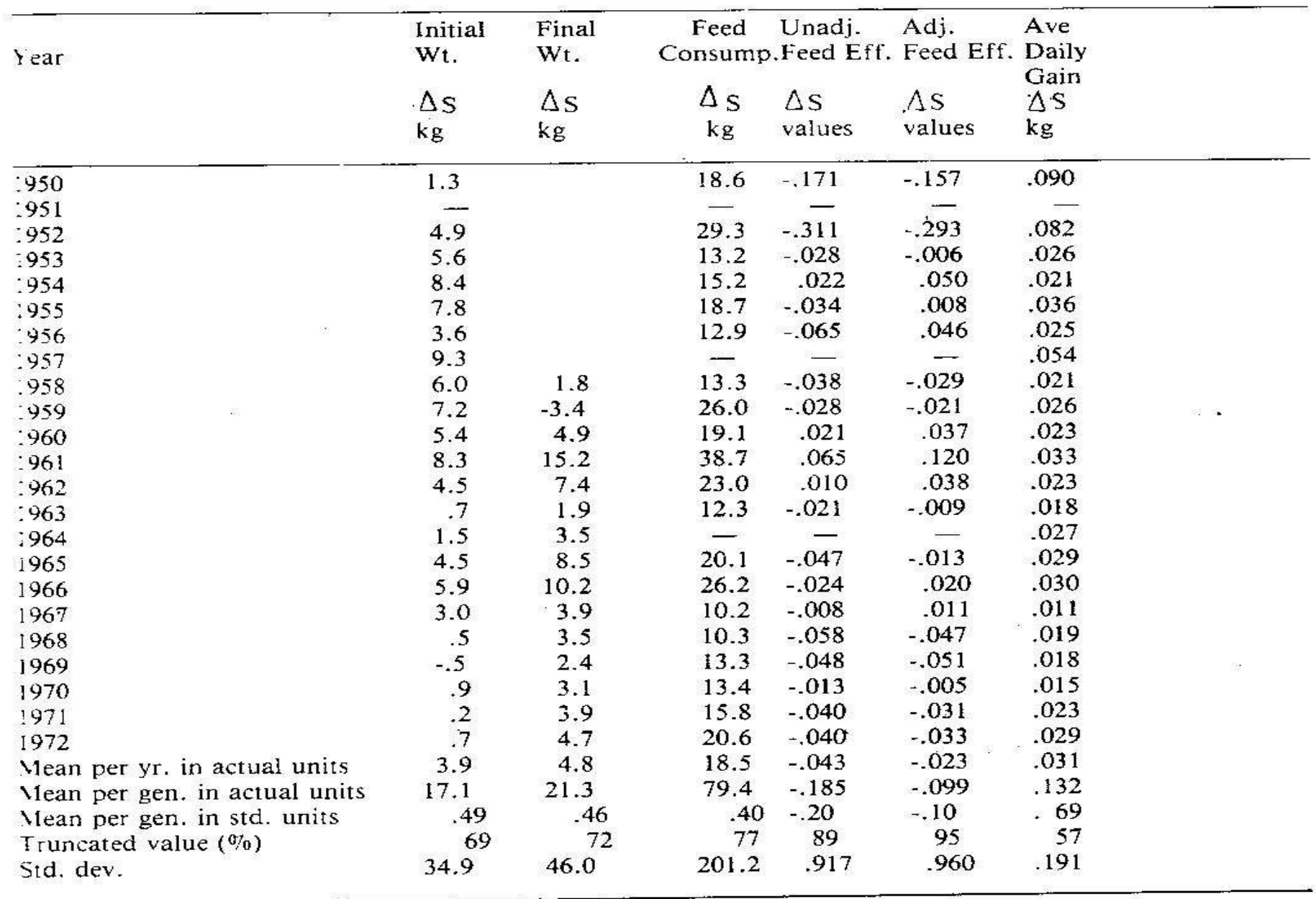


NWAKALOR $E T A L$

TABLE 7

Pooled annual Selection Differentials $(\mathrm{kg})$ over all Lines for Postweaning Traits of inbred Females

\begin{tabular}{|c|c|c|c|c|c|c|c|}
\hline \multirow[b]{2}{*}{ Year } & \multicolumn{2}{|c|}{ Yearling Traits } & & & \multicolumn{3}{|c|}{ Mature Cow Wts. } \\
\hline & $\begin{array}{l}\text { Gain } \\
\text { WN-12 } \\
\Delta{ }^{\text {mo. }}\end{array}$ & $\begin{array}{l}\text { 12-mo } \\
W t \\
\Delta D\end{array}$ & $\begin{array}{c}\text { Gain } \\
12-18 \\
\text { mo. } \\
\Delta \mathrm{D}\end{array}$ & $\begin{array}{l}\text { 18-mo. } \\
\text { Wt. } \\
\Delta \mathrm{D}\end{array}$ & $\begin{array}{l}\text { Spring } \\
\text { Wt. } \\
\Delta D\end{array}$ & $\begin{array}{l}\text { Summer } \\
W_{L} \text {. } \\
\Delta D\end{array}$ & $\begin{array}{l}\text { Fall } \\
W_{t} . \\
\Delta D\end{array}$ \\
\hline 1949 & .5 & -.2 & -2.3 & -2.5 & -5.8 & -15.7 & -14.0 \\
\hline 1950 & - & - & - & 2.1 & -2.1 & .0 & .7 \\
\hline 1951 & - & - & - & 1.5 & .9 & $2 . ?$ & .5 \\
\hline 1952 & .5 & .9 & .1 & 1.5 & 2.1 & $2.1:$ & 2.2 \\
\hline 1953 & .5 & 4.2 & -1.1 & 1.1 & 3.1 & 3.2 & 3.8 \\
\hline 1954 & .2 & -2.9 & -.3 & -1.0 & -2.2 & -3.2 & -3.0 \\
\hline 1955 & - & .0 & .0 & 1.6 & 1.6 & 1.5 & 1.8 \\
\hline 1956 & .4 & 4.8 & - & - & 1.2 & .9 & 1.5 \\
\hline 1957 & -.5 & .6 & .0 & 1.0 & -1.5 & -1.2 & -1.2 \\
\hline 1958 & -.4 & -2.1 & -.8 & -.3 & -1.6 & -1.3 & -1.6 \\
\hline 1959 & - & - & - & .1 & -1.3 & -1.7 & -.8 \\
\hline 1960 & .0 & -.1 & .2 & .0 & -.2 & -.4 & -.5 \\
\hline 1961 & - & - & - & .0 & -1.6 & -2.0 & -1.5 \\
\hline 1962 & -.1 & .2 & .1 & .0 & .0 & .1 & .4 \\
\hline 1963 & .4 & .9 & .5 & .9 & -.3 & .0 & -.7 \\
\hline 1964 & -.4 & .6 & -.7 & .2 & -1.4 & -.8 & -.9 \\
\hline 1965 & .0 & -.1 & .0 & -.1 & -.1 & .5 & .3 \\
\hline 1966 & .1 & -.6 & 1.3 & .8 & -.1 & .6 & .7 \\
\hline 1967 & .3 & .2 & -1.1 & -1.2 & -1.8 & 1.5 & -1.9 \\
\hline 1968 & .0 & .8 & -.2 & -.1 & 1.2 & 1.0 & 1.0 \\
\hline 1969 & -.1 & .4 & .5 & .9 & -.4 & -.2 & -.1 \\
\hline 1970 & .1 & 1.0 & -.5 & -1.1 & -3.3 & -3.1 & -3.3 \\
\hline 1971 & .2 & .5 & -.7 & -.5 & -1 & .5 & .6 \\
\hline 1972 & -.5 & 9 & -.4 & -1.1 & -3.4 & -3.6 & -3.6 \\
\hline 1973 & .0 & 1.4 & 1.0 & .0 & - & - & - \\
\hline Mean per yr. in actual units & .0 & .2 & -.2 & .1 & -1.0 & -1.1 & -1.0 \\
\hline Mean per gen. in actual units & -.2 & 1.0 & +1.0 & .6 & -3.9 & -4.9 & -4.3 \\
\hline Mean per gen. in std. units & -.026 & .040 & -.076 & .020 & -.090 & .101 & -.090 \\
\hline Truncated value $\%$ & (99) & 98 & $(96)$ & 99 & (96) & (95) & (96) \\
\hline Std. dev. & 8.7 & 25.0 & 13.2 & 30.1 & 43.4 & 48.4 & 47.3 \\
\hline
\end{tabular}

() Selected individuals represent the lower segment of the population. 
SELECTION INTENSITY AND GEN INTERVAL IN HEREFORD CATTLE.

TABLE 8

Annual Selection Differentials (kg) for Postweaning Traits of Lineoross Females

\begin{tabular}{|c|c|c|c|c|c|c|c|c|}
\hline \multirow[b]{3}{*}{ Year } & \multicolumn{4}{|c|}{ Yearling Traits } & \multicolumn{4}{|c|}{ Mature Cow Wts. } \\
\hline & $\begin{array}{l}\text { Gain } \\
\text { WN-12 } \\
\text { mo. }\end{array}$ & $\begin{array}{l}\text { 12-month } \\
\text { Wt. }\end{array}$ & $\begin{array}{c}\text { Gain } \\
12-18 \\
\text { mo. }\end{array}$ & $\begin{array}{l}\text { 18-month } \\
\text { Wt. }\end{array}$ & $\begin{array}{l}\text { Spring } \\
\text { Wt. }\end{array}$ & $\begin{array}{l}\text { Summer } \\
\text { wt. }\end{array}$ & $\begin{array}{l}\text { Fall } \\
\text { Wt. }\end{array}$ & \\
\hline & $\Delta \mathrm{D}$ & $\mathrm{dD}$ & $\Delta \mathrm{D}$ & $\Delta D$ & $\Delta \mathrm{D}$ & $\Delta \mathrm{D}$ & $\Delta D$ & \\
\hline 1949 & -3.4 & -11.8 & 5.7 & -3.5 & 10.2 & 4.2 & 3.5 & \\
\hline 1950 & - & - & - & 1.7 & .0 & .0 & .0 & \\
\hline 1951 & - & 一 & - & -1.0 & -2.2 & -3.5 & -3.2 & \\
\hline 1952 & -.6 & -1.1 & .5 & .1 & 2.5 & 2.9 & 3.2 & \\
\hline 1953 & -.1 & -.1 & .7 & .7 & 3.1 & 3.3 & 3.5 & \\
\hline 1954 & 1.7 & 1.7 & -1.4 & -1.3 & -3.4 & -3.4 & -3.0 & \\
\hline 4955 & - & - & - & -.1 & 2.9 & 3.5 & 2.0 & \\
\hline ¿956 & 2.8 & 4.7 & - & - & 1.0 & .2 & 2.4 & \\
\hline$: 957$ & - & - & - & - & .0 & .0 & .0 & \\
\hline 1958 & .1 & -.8 & -.3 & -1.0 & -1.2 & -.9 & -1.1 & \\
\hline 1959 & - & - & - & .2 & .5 & 1.1 & .8 & \\
\hline 1960 & .0 & -.5 & .2 & 1.0 & 1.8 & 2.3 & 2.1 & \\
\hline 1961 & - & - & - & -.8 & -2.5 & -2.6 & -2.8 & \\
\hline 1962 & -.2 & -.4 & .2 & .0 & -.9 & -.5 & -.3 & \\
\hline 1963 & .4 & .9 & -1.3 & -.5 & -.1 & .1 & -.4 & \\
\hline 1964 & .0 & -.1 & -.1 & .6 & -.8 & -.6 & -.3 & \\
\hline 1965 & -.4 & -2.2 & .4 & .0 & .0 & .6 & 1.0 & \\
\hline 1966 & 1.2 & 2.5 & -1.5 & .2 & 1.3 & 1.4 & 1.6 & \\
\hline 1967 & .2 & .8 & -.9 & -.4 & -1.5 & -1.5 & 1.8 & \\
\hline 1968 & .4 & 1.7 & .5 & 1.6 & 1.5 & 1.5 & 1.4 & \\
\hline 1969 & .0 & -1.0 & .2 & -.7 & -2.7 & -2.3 & -3.1 & \\
\hline 1970 & .2 & .0 & .1 & $\cdot .3$ & .3 & .5 & .7 & \\
\hline 1971 & -.2 & -.4 & .6 & .1 & .7 & .7 & .4 & \\
\hline 1972 & .2 & 1.8 & .5 & 2.6 & .3 & .3 & .4 & \\
\hline 1973. & -.1 & .0 & .1 & -.2 & - & - & - & \\
\hline Mean per уг. in actual units & .1 & -.2 & .2 & .0 & .5 & .3 & .3 & \\
\hline Mean per gen. in actual units & .4 & -1.0 & 1.0 & .0 & 2.0 & 1.4 & 1.2 & \\
\hline Mean per gen. in std. units & .040 & -.040 & .083 & .000 & .046 & .031 & .026 & \\
\hline Truncated value $(\%)$ & 98 . & (98) & 96 & 100 & 98 & 99 & 99 & \\
\hline Std. dev. & 10.3 & 25.9 & 12.5 & 28.7 & 42.5 & 44.2 & 44.6 & \\
\hline
\end{tabular}

() Selected individuals represent the lower segment of the population.

Previous studies (Brinks et al 1961; Armstrong, 1964; Flower et al., 1964; Brinks et al 1965) reported variable but positive selection intensity for weaning weight. Other researchers (Koch, 1973; Chapman, et al 1972; Koch et al, 1964; Stanforth and Frahm, 1975) report positive and relatively intense selection pressure for the same trait. In all cases much greater pressure was applied in male than in female selection.
Postweaning Traits in Males. The selection differentials of sires for postweaning traits of males are presented in table 6 . Annual selection differentials were fairly consistent for all traits except initial test weight in which there appears to have been a decline after 1967, and were positive in all years for feed consumption and average daily gain.

Average annual selection differentials were $3.9 \mathrm{~kg}$ for initial weight, $4.8 \mathrm{~kg}$ for 
TABLE 9

Phenotypic Correlations and Selection Differentials (per Generation in Standard Measure) used to calculate Selection Indexes in Retrospect

\begin{tabular}{lcccc}
\hline & \multicolumn{3}{c}{ Males } \\
Trait & WW & FE & ADG & $\mathrm{S}$ \\
\hline $\begin{array}{l}\text { Weaning weight (WW) } \\
\text { Feed efficiency (FE) }\end{array}$ & 1.00 & .03 & .17 & .55 \\
Average daily gain (ADG) & & 1.00 & -.17 & -.10 \\
& & 1.00 & .69
\end{tabular}

\begin{tabular}{|c|c|c|c|c|c|c|c|}
\hline \multirow[b]{2}{*}{ Trait } & \multicolumn{5}{|c|}{ Females } & \multicolumn{2}{|c|}{$\Delta D$} \\
\hline & ww & $12 W$ & $18 \mathrm{~W}$. & SPW & FAW & Inbred & Linecross \\
\hline Weaning weight (WW)a & 1.00 & .73 & .64 & .45 & .45 & .11 & .10 \\
\hline 12-mo. wt. (12W) & & 1.00 & .82 & .57 & .57 & .04 & -.04 \\
\hline 18-mo. wt. (18w) & & & 1.00 & .67 & .67 & .02 & .00 \\
\hline Mature spring wt. (SPW) & & & & 1.00 & .87 & -.09 & .05 \\
\hline Mature fall wt. (FAW) & & & & & 1.00 & -.09 & .03 \\
\hline
\end{tabular}

${ }_{\text {Adjusted for inbreeding effects }}$

bAdjusted for differences in body weight.

TABLE 10.

Selection Indexes in Standard Measure for Sires and Dams

\begin{tabular}{lllllll}
\hline & & \multicolumn{5}{c}{ Inbred Sires } \\
\hline Index & WW & FE & ADG & $I_{s}$ & \\
\hline $1^{\mathrm{a}}$ & & & & & & \\
$2^{\mathrm{b}}$ & .4461 & -.0092 & .6126 & .818 & & \\
Index & .3945 & -.0061 & .6219 & .792 & FAW & $\mathrm{I}_{\mathrm{D}}$ \\
\hline
\end{tabular}

$\mathbf{1}^{\mathrm{c}}$

$\begin{array}{llllll}.1824 & -.0284 & .0736 & -.1097 & -.1097 & .203 \\ .2690 & -.0826 & .0636 & -.1105 & -.1105 & .241\end{array}$

Linecross Dams

$\begin{array}{llllll}.2693 & -.2960 & .0147 & .1185 & -.0354 & .209\end{array}$

With weaning weight adjusted for inbreeding and feed efficiency adjusted to common body weight.

bith weaning weight unadjusted for inbreeding and feed efficiency adjusted to common body weight.

CWith weaning weight adjusted for inbreeding.

dwith weaning weight unadjusted for inbreeding. 
Iinal weight. $18.5 \mathrm{~kg}$ for feed consumpjon, - .043 for unadjusted feed efficien$\mathrm{iy},-.023$ for adjusted feed efficiency, and $.031 \mathrm{~kg}$ for average daily gain. In standard units these were $.49, .46, .40$, $-.20,-.10$ and .69 per generation and correspond to saving the top $69,72,77$, 89,95 and 57 percent of the bulls, respectively, for use as herd sires. Negative selection differentials would be expected for feed efficiency since lower feed intake per unit of gain is-advantageous. Apparently, these do not represent very intense selection, but considering that selection was not for single traits, the overall selection pressure for postweaning traits in bulls may be considered reasonable.

Postweaning Traits in Females. Annual selection differentials for postweaning traits in inbred females (table 7) show some consistency over the year. Mean annual selection differentials were zero and $-.2 \mathrm{~kg}$ for gains from weaning to 12 months and 12 to 18 months, but positive for 12- and 18-month weights, being .2 and $.1 \mathrm{~kg}$. Annual selection differentials for mature cow weights were all negative on the average. These were $-1.0,-1.1$ and $-1.0 \mathrm{~kg}$, respectively, for spring, summer and fall weights. The average standardized selection differential per generation and the percent of the population represented by the selected females were, respectively: - 026 and 99 for postweaning gain to 12 months, .040 and 98 for 12-month weight, -.076 and 96 for mature spring weight, -.101 and 95 for mature summer weight, and -.090 and 96 for mature fall weight. With the exception of 12- and 18-month weights for which selection was for the top percentage of the population, the selected individuals for other traits represent the lower segment of the population. These results indicate that selection was not intense on inbred dams. Selection differentials for mature weights might be biased since selection of females was done at weaning time.
The selection differentials for linecross females are listed in table 8 . Average annual selection differentials were small but positive for all traits except 12- and 18-month weights which amounted to - .2 and zero, respectively. In standard measure per generation, the average values were $\mathbf{0 4 0}$ for gain from weaning to 12 months, -.040 for 12 -month weight, .083. for gain from 12 to 18 months, zero for 18-month weight. .046 for mature spring weight, .031 for mature summer weight, and .026 for mature fall weight. These values (except for 12-month weight which represent selection of the lower segment) indicate that about the upper 98 percent of the linecross female population were retained for breeding. Therefore, selection of linecross dams for postweaning traits also was not intense.

General Discussion on Postweaning Traits. Armstrong (1964) reported higher selection pressure on the sires, amounting to $.70, .90$ and .78 standard deviations per generation for initial weight, final weight and average daily gain and a positive selection pressure of -.33 standard deviations for feed efficiency for bulls. Brinks, Clark and Kieffer (1965) revealed that selection of sires was fairly intense for postweaning traits, averaging 1.10 and 1.46 standard deviations per generation for 196-day gain and final weight off test. In conformity with the results of the present study, selection was not intense for any of the postweaning traits in females. Koch, Gregory and Cundiff (1974) report much larger selection differentials representing 79 to 88 percent of actual midparent selection differentials in the three lines studied. A similar study by Stanforth and Frahm (1975) showed that male selection accounted for 80 and 83 percent of the primary selection differentials for weaning and yearling weights. Nelms and Stratton (1967) reported average annual midparent standardized selection differential of $\mathbf{. 1 4 2}$ for postweaning daily gain and .190 for final 


\section{NWA TALOR ET AL}

weight. Other studies (Flower et al., 1964; Chapman, Clyburn and McCormick, 1969; Bailey et al, 1971; Chapman, Clyburn and McCormick, 1972) showed that selection for postweaning traits was fairly intense on the males and much less on the females. In some cases little or no selection was practised for females.

In the present study, the inclusion of sire selection differentials of some foundation animals in the annual weighted average could have caused a downward bias in the selection differentials. However, our results and those reported in the literature indicate that most of the midparent selection pressure for weaning weight and postweaning traits was applied in male selection and was expected.

Selection Indexes in Retrospect. Indexes actually practised were determined in retrospect for inbred sires, inbred dams and linecross dams. The index for.inbred males included adjusted weaning weight, feed efficiency (adjusted) and postweaning average daily gain. Initial weight, final weight, and feed consumption were not included in the index since these are accounted for, respectively, by weaning weight, average daily gain and feed efficiency. Female indexes consisted of adjusted weaning weight, 12-month weight, 18-month weight, mature spring weight and mature full weight. Postweaning gains were not included since these are fully described by the various weights.

The phenotypic correlations and selection differentials used to calculate the indexes are shown in Table 9. In each case the correlation matrix (as the independent variables) was equated to the selection differential of selected parents (as the dependent variable). Solutions of the equations yielded the standard partial regression coefficients (the relative weights) for the indexes actually practised as shown in Table 10. Sire indexes show that rate of gain after weaning received the greatest emphasis and had about one and one-half times the weight given to weaning weight. Although feed efficiency received attention in the expected direction, it did not contribute significantly to the index. In both the inbred and linecross dam indexes weaning weight had the greatest emphasis and was expected since selection of heifers for replacement was done at weaning time.

The standard partial regression coefficients of .4461 and .3945 for weaning weight and .6126 and .6219 for average daily gain were close to .4231 and .5769 obtained for the same herd, respectively, for weaning weight and average daily gain by Armstrong (1964). The author also reported much more attention to average daily gain than any other trait included in the index. Even though Brinks, Clark and Kieffer (1965) did not. consider average daily gain directly in the sire index, they report that final weight off test received much more emphasis than weights or scores recorded before final weight. Koch, Gregory and Gundiff (1974) noted greatest emphasis for weaning weight in the sire index for weaning weight line, for yearling weight line, and for muscling score in the sire index for yearling weight and muscling score line. Our sire index selection differentials in standard mesures of .818 and .792 were similar to .86 and .89 obtained by Armstrong (1964) but were lower than those reported by Brinks, Clark and Kieffer (1965) and Koch, Gregory and Gundiff (1974). There was much greater opportunity for selection in sires than in dams due to a smaller fraction needed for replacement. Sire index selection differentials represented about 79 percent of the total selection differentials. In practical terms index practised in retrospect represents the average weighting actually used in any particular year and line.

Even though these findings were obtained from a study in a temperate environment, they could have wide applicability in the humid tropical Nigerian climate. Genetic improvement of beef cattle or any other class of livestock for that mater in Nigeria, will require breeders to embark on selection programmes aimed at increasing the frequency of desirable genes for economic traits, hence the mean performance of different populations. 
Such breeders will need to keep accurate records of performance of animals in order to aid selection. By applying intense selection pressure especially on sires and decreasing the generation interval, rapid genetic progress per year should be expected for traits of moderate to high heritabilities. Moreover, the creation of inbred lines, intense selection practice between and within the lines and subsequent crossing of the lines to exploit heterosis, are possible strategies for increased beef production in Nigeria.

\section{THWDINCXS}

ARMSTrong, \& J.B. 1964. Evaluation of selection intensity and genetic changes in experimental herd of Hereford cattle. Ph.D. Thesis, Colorado State University, Fort Collins.

Bailey, C.M., Harvey, W.R., Hunter, J.E. and TORELL, C.R. 1971. Estimated direct and correlated response to selection for performance traits in close Hereford lines under different types of environments. J. Anim. Sci. 33; $541-549$.

Brinks, J.S., ClARK, R.T., KIEFFER, N.M. and QUESENBERRY, J.R. 1962. Mature weight in Hereford range cows: heritability, repeatability and relationship to calf performance. J. Anim. Sci. 21: $501-504$.

Brinks, J.S., Clark, R.T., KIEFFER, N.M. and URICK, J.J., 1964. Estimates of genetic, environmental and phenotypic parametes in range Hereford females. J. Anim. Sci. 23: 711-716.

Brinks, J.S., Clark, R.T. and KiefFer, N.M. 1965. Evaluation of response to selection and inbreeding in a closed line of Hereford cattle. U.S.D.A. Tech. Bull. 132?

Brinks, J.S., Clark, R.T. and Rice, F.J. 1961.. Estimation of genetic trends in beef cattle. $J$. Anim. Sci. 20; 903 (Abstr.).

Chapman, H.D., Clyeurn, T.M. and McCormick, W.C. 1969. Selection of beef cattle for single traits. J. Anim. Sci. 29; 225-232.

ChapMan, H.D., Clyburn. T.M. and MoCommok, W.C. 1972. Comparison' of criteria for selecting introduced beef sires. J. Anim. Sci. 35; $321-326$.

Dickerson, G.E. and Hazel, L.N. 1944. Effectiveness of selection on progeny performance as a supplement to earlier culling in livestock. J. Agr. Res. 69; 459 -475.

Dickerson, G.E., Blunn, C.T., Chapman, A.B., KOTTMAN, R.M., KRIDER, J.L., WARWICK, E.J., and WHATLEY, J.A., Jr. 1954. Evaluation of selection in developing inored lines of swine. North Central Regional Pub. 38, Mo. Agr. Sta. Res. Bull. 551; 60pp.

Flower, A.E., Brinks, J.S., URICK, J.J. and WILLSON, F.S. 1964. Selection intensities and time trends for performance traits in range Hereford cattle under mass and recurrent selection. J. Anim. Sci. 23; $189-195$.

HaRvey, W.R. and Bearden, G.D.; 1962. Tables of expected genetic progress in each of two traits. USDA Agr. Res. Service, ARS 20-12.

HARWIN, G.O. 1963. The effect of inbreeding anc environmental factors on the weaning weight anc postweaning growth of range Hereford cattle Ph.D. Thesis, Colorado States University, For Collins.

JAMES, J.W. 1972. Optimum selection intensities in breeding programs. Anim. Prod. 14; $1-9$.

Kock. R.M. 1973 Selection for weaning weight, yearling weight and muscling in beef cattle. In U.S. Meat Animal Research Centre 1973 Beef Cattle Research Progress Report. 79 pp.

Koch, R.M., Gregory, K.E. and Gundiff, L.V. 1974. Selection in beef cattle. I. Selection applied and generation interval. J. Anim. Sci. 39; $449-458$.

Nelms, G.E. and Stratton, P.O. 1967. Selection practised and phenotypic change in a closed line of beef cattle. J. Anim. Sci. 26: 274-277.

Nwakalor, L.N., Brinks, J.S. and Richardson, G.V. 1976. Estimated genetic change in weaning weight of beef cattle. J. Anim. Sci. 43: 396-403.

Petty, R.R. and Cartwright, T.C., 1966. A summary of genetic and environmental statistics for growth and conformation traits of young beef cattle. Texas Agr. Exp. Sta. Dept. Anim. Sci. Tech. Rep. 5.

Preston, J.M. and Willis, M.B. 1974. 
Intensive Beef Production. Pergamon Press. 544 pp.

Rendel, J.M: and Robertson, Alan. 1950. Estimation of genetic gain in milk yield by selection in a closed herd of dairy cattle. J. Genetics. 50: 1-8.
Stanforth, T.A. and Frahm, R.R. 1975. Selection for weaning and yearling weight in Hereford cattle. J. Anim. Sci. 14: 259. (Abstr.) 